\title{
The challenges of sustainable development and architecture
}

\author{
Shaham Asadi ${ }^{1, ~ *, ~ M e h r d a d ~ F a r r o k h i ~}{ }^{2}$ \\ ${ }^{1}$ Department of Architecture, Higher Education Institute Rozbeh, Zanjan, Iran \\ ${ }^{2}$ Department of Architecture, Mohaggegi Ardabili University, Ardabil, Iran
}

Email address:

Shahamasadi@gmail.com (S. Asadi), Mehrdad.farrokhi@gmail.com (M. Farrokhi)

\section{To cite this article:}

Shaham Asadi, Mehrdad Farrokhi. The Challenges of Sustainable Development and Architecture. International Journal of Science, Technology and Society. Special Issue: Research and Practice in Architecture and Urban Studies in Developing Countries.

Vol. 3, No. 2-1, 2015, pp. 11-17. doi: 10.11648/j.ijsts.s.2015030201.13

\begin{abstract}
Ignoring sustainable development leads on to destruction of the environment and humankind. This thought in third world is copied from developed countries, without preserving the collective identity in the community in which historical and cultural approaches are one of the main heritages. The identity crises are to some extent caused by architect's actions, since they consider the environment more important than cultural and social issues. Sustainable development looks at architecture with modernistic approach. Sustainable Architecture and urban designing are not a common - international concept of communities, cultures and people of every community. Beside scientific and new global experiences, we should define sustainability with decent comprehension of history, culture, climate and main infrastructures. Sustainable architecture has a postmodernist point of view about objects and never directs its attention to just one main global idea, ignoring the culture and environment, and never puts mechanic outlook on architecture or urban designing. Method of research in this paper is based on the description and analyses of sustainable architecture by using other literatures. This paper tries to show the process of sustainable development evolution and the viewpoint of sustainable architecture as well as sustainable development in order to decide whether this idea responds the crisis age needs.
\end{abstract}

Keywords: Sustainable Development, Sustainable Architecture, Identity

\section{Introduction}

Buildings and the built environment play a major role in the human impact on the natural environment and on the quality of life. Architecture is normally built and meant to stay in a useful order for at least several decades or even hundreds of years. Its performance, whether negative or positive, will cause an impact on the environment throughout its life span. Moreover, according to Brian Edwards, architecture is responsible for about half of total global resource consumption due to the use of materials, energy, water, and the loss of fertile farmland which is replaced by buildings [1].

Since architecture and environment have a close relationship in terms of cause and effect, better building and a more sustainable architecture will be one of the solutions toward sustainability [16].

Main foundations of sustainable architecture include three different approaches: "Economy", "society" and "environment". there is one forgotten thing here that is society and culture as a main real identity phenomenon.Even famous architects like Foster don't notice it. He is a high-tech architect and one of the disciples of modern architecture. Modernity thinks identity and personality of mankind can be reviewed, on the other hand, man sees himself through overwhelming different desires, so he is confused about selecting anything, actually a deep modern man faces so many dilemmas [6].

Modern architecture doesn't look to the nature honestly, it wants to colonize and reform the organic form of nature in order to make a settlement against the surrounding, and tries to dominate the nature,this point of view comes from the positivistic look of modern architecture to technology and ecologic problems.

Among other important elements of western society that leads them to decay, identity crisis shows itself in the form of, being hostage tothe mechanism, the Proletariat and the Corruption that comes from the worship of power [23]. Dr. 
Shariati [31]. thinks the mechanism is a specific order, a society phenomenon and exposed by exclusive ownership. Ancient humans liveswere limited only to provision of shelter and protection from wild animals, regardless of the form convenience and environmental impacts [28]. So for a better implementation of process of architecture and sustainable development in our country we have tonotice not only energy consumption, but also consider our culture as a main and unchanging element.

As the development of society continues, healthy, comfortable and non-polluting energy saving living conditions are needed and thus an integrated building space is created which combines the beauty of form, the natural environment and historical culture all together [33].

\section{The Reasons for the Formation of Sustainability Concept}

In Dehkhoda dictionary, sustainabilityis defined as a durable and lasting thing. In Moein dictionary's definition,it means being stable and resistant. The verb sustain comes from the Latin word, Sustinere, Sus (means from down to up) and Tinere (means keeping and preservation), this word has been used in English since 1290 AD [35].

This viewpoint is based on holistic and interconnectedness, and looks to three fundamental issues economy, society and environment simultaneously. In 1970s, considering the war between Arabs and Israel, the price of crude oil increased unprecedentedly and the industrial countries faced hard situation.

This crisis forced those countries to find ways to be independent of middle east oil. The term sustainable development was used formally for the first time in 1987. In recent years we have just noticed in the environment and forgotten the two others [15]. In 1970s, rapid growth of development programs, whether consciously or not, caused social, economic and environmental threats. The goal of the term sustainability mentioned formally for the first time by "Brandt Land" in report of our common future in 1987 was to reach theoptimal consumption pattern [27].

The tipping point of these arguments was in 1922, world conference on sustainable development, known as the Earth summit in Rio de Janeiro-Brazil, later known as the Rio summit [35].

Human life always depends on the natural resources. This dependence became more evident, after the industrial revolution and led to the indiscriminate use of natural resources, non-renewable energies and fossil fuel by humans.

Risk of running out of non-renewable resources and danger of ecological problems like global warming, perforation of ozone layer, air pollution etc.triggered movements towards ecological sustainability and then pervasive global movements in sustainable development in late 20th century [27]. Overcrowding and consequential unplanned growth have resulted in environmental degradation on A variety of scales.
This is inclusive of localized environmental health problems, such as indoor air pollution and contamination of drinking water, and city-regional environmental problems such as ambient air pollution, inadequate waste management and resultant pollution of water-bodies such as rivers and lakes [10].There are so many risks facing modern man, for example we can mention Cristopher Alexander's worries about population. He says: "most of the comments and foresights about population explosion, relates to economic factors, especially dearth of food and end of natural resources. But there is another huge risk, destruction of beauty.Human's health as a living creature depends on physical, nervous and emotional effects of the environment [13]. These reasons show that we have to work on the topic in universal level for evolving the process of residence on earth.

\section{Sustainable Development and Empowerment}

Empowerment should be the ultimate goal of any community development projects. While Development often interpreted as the flow of resources from outside into community, empowerment push and- pull full participation of all community members to change their world by them self, from inside to outside [3].

Sustainable development wants to make major changesin comprehension of the relation between humanity and nature, but the solutions for built environment and architecture are still mechanical and modern.it seems that In most of sustainable architectures and development theories presence of the modernistic ideas of Bacon is felt. He says " the world is made for human and not human for the world".It means using and exploiting the nature with no destruction for more utilization [13].

This fact also includes society. Speer and Hughey concluded that community organization is an important way to reach empowerment. They stated that it is tightly related to the ecology of local community, how any outsiders must pay attention to the psychological condition of community in order to reach social power as the predecessor of empowerment [3].

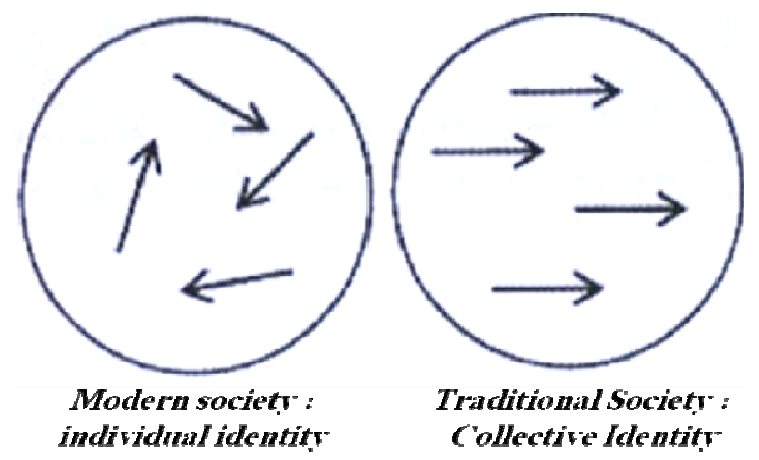

Figure 1. Human relations in modern society and traditional, Hojjat,2005:85

The systematic look of this subject is to systematize 
society in order to achieve macro-objectives and create a socialist perspective. society enabling without making infrastructures is nonsense. During any period of time getting the psychological and physicalstate of society, just for dominating the culture and identity of a country and giving a fake identity for more power, is usual.In the Adhiutama's article we noticea gradual overcoming of modern thoughts on developing communities who thinkthe only way to develop is to use development schema of westerns. Obviously, modern thoughtin the form ofsustainable development penetrates developing communities.

The sustainable development structure will meet the needs of the present and nextgeneration. It considers subject with broad and equalvision.

Dr. Shariti [31] thinks the relations between this Age's personsare based on common sense, In the past itwas because of instinct, emotion and moralities. According to the idea, modern man is wiser than a traditional one, but we should consider that he is unable to solve an emotional crisis.

As you know Bacon was eager to build a new science in order to dominate the nature.Amodern man wants to have fun in this world,He always tries to satisfy this desire by use of mind [17].(see figure 1)

Western sciences are humanistic and rule our mind. Actually, developed countries impose them on developing countries in order to sell their products like culture, identity, materials etc.

Community with lack of development must be developed through community development. Then, the increasing of knowledge's will sustain the development. After that, the transformation process should be continued to reach beyond sustainable development that is empowerment. As the booster of transformation process, appropriate technology should also be implemented through several stages in order to ensure the growth of effects of technology implementation. The stages include the participation of three main parties in community empowerment projects, which also include existing appropriate technology as well as sustainable development thoughts into account [3].

The term "sustainable" is often interpreted as the final solution of development .However, contradictive result is also often detected when the sustainable development is mostly given by the intervention of outsiders to rural community [3].

\section{Factors that Influence Sustainable Development}

Based on the results of our research the following major aspects were identified: economic, political, technological, social and ecological.

Sustainable construction develops providing integrated approach and revealing of existing differences. Taking into account that the concept "construction" in wider meaning includes the construction industry, the public authorities supervising of the construction industry, construction merchants and non-governmental organization of builders, within framework of the study the focus is on construction.

The systemic approach is used to tackle sustainable development problems on a local, national, international and global level [32]. Sustainable development is a complex relationship between architecture and three other departments and general concepts in human ecology with sustainable development economy on the simultaneously.

To realize the sustainable design process, we simply use the three - rings diagrams to illustrate the dependence of the stability connecting the components. In Figure 2, sustainability contains four parts: low carbon economy, society, natural environment and architecture. Each part has subsequent factors shown as below.

- Natural environment: Orientation, Climate, Infrastructure, Light/ Space/ Ventilation, Energy/ Water.

- Low Carbon economy: Added Value, Flexibility, Commercial Reality, Longevity.

- Society: Culture, Social Benefits, People, Health and Well-being.

- Architecture: Form and Function, Identity, Structure, Materials, Innovation

We conclude that architecture is not only an exercise judiciously balancing considerations internal to the building. The building itself enters into a complex whole where the successful resolution of the project depends on the achievement of a harmonious dynamic interplay between the architecture and the surroundings that as three rings shown in Figure 2 [34].

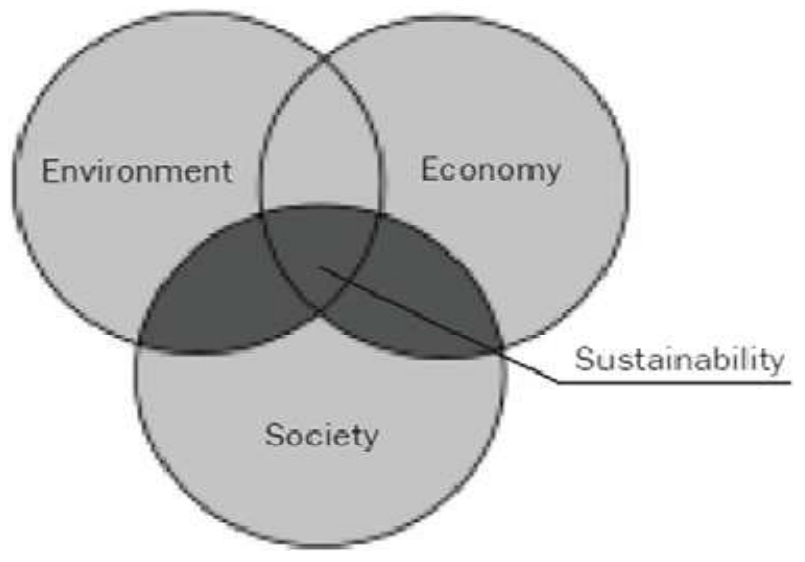

Figure 2. Three rings of sustainable design AbdelAziz \& M. Shawket, 2011:229

In the following text, we describe the above-mentioned factors in detail.

\subsection{Environmental Sustainability}

Green architecture and sustainable development is the inexorable trend for the future of architecture design. On the basis of meeting the function of residence, human beings can combine the esthetic arts and the eco-culture of architecture to express their traditional historical culture, strengthen the recognition of the eco-culture of architecture, promote the aesthetic consciousness of the whole nation and root the 
concept of green architecture, energy saving and sustainable development deeply into people's hearts by applying new technology, new construction materials and new techniques [33].

The housing industry is a major contributor to climate change, resource depletion and pollution at a global level. Therefore, environmental protection should be thought of and be important [9]. Environmental sustainability prevents harmful and irreversible effects on the environment by the efficient use of natural resources, encouraging renewable resources, as well as protecting the soil, water and air from contamination [2]. Environmental sustainability is also concerned with the extraction of natural resources. Although builders have little influence over the extraction of natural resources, they can help discourage this activity by demanding less non-renewable natural resources, more recycled materials, and the efficient use of energy and mineral resources [30].

Dr. Nasr [21] explains in his book "human and nature", to be in peace with nature, we have to be in peace with spirituality and to be in peace with the earth, we have to be in peace with sky. For regaining the sacred and spiritual values of nature, there is no other choice than renovating Metaphysics.

Considerations on development of buildings must be taken into account in sustainable design. Based on analysis of core function and possibilities for flexibility over time of buildings and its surroundings, it is important to seek to humanize the built environment by designing buildings in tune with their context and resonating sense of place [34].

\subsection{Social Sustainability}

Sustainability plays a powerful role at a social level; that is to say, having the ability to provide access to good education, creating goodwill, improving community consultation and promoting interest in various fields. Firstly, significant issues influencing the area such as poor health, crime, and social exceptions should be considered, before any action to make an area more sustainable can be undertaken [7].

In addition, social well-being is concerned with the benefits to both workers and future users. Basically, this aspect is concerned with human feelings: security, satisfaction, safety, comfort [19]. and human contributions such as: skills, health, knowledge and motivation [26]. Architectural culture is a phenomenon that changes from time to time because of the changes in thinking of each Age. So designers should lan the existing culture, environmental features and design space for better social sustainable designs and avoid identity crisis. Architecture consists of two parts, firstly, what to build (a cultural issue)secondlyis, how to build (a technological issue) [11].

\subsection{Economic Sustainability}

From on economic sustainability perspective, sustainability issues deal with a wide range of factors within both the local and global level [12].
The main economic drivers of adopting sustainable principles are the enhancement of property performance and durability as a result of the maintenance and operational costs for the duration of the life cycle of the housing project. Implementing sustainable principles can also provide excellent living and working spaces resulting in increased employee productivity levels [36]. According to Abidin and Pasquire [2], economic sustainability increases profitability through the efficient use of resources (human, material and financial).

On the other hand, in terms of economic sustainability, construction industry must consider housing affordability, housing life cycle cost, expenditure on renovating and developing, business enhancement, legislation compliance, profitability and risk management [30].

During recent years, the development of passive low energy architecture has referred low carbon architecture in the context of sustainability. Hence, we may redefine the low carbon architecture as a sustainable architecture base on a human ecology with the sustainable development of economy, society and architecture simultaneously [34].

Dr. Krishan thinks: The relationship between built form and the environment is the driving force behind this process, based on a scientific methodology. Therefore, it seems logical to develop a process almost in the form of an algorithm which will help find the optimal solution / form for a given set of parameters and constraints. Evidently based on a design hypothesis it is possible to generate a set of solutions through this process / algorithm. From this set of solutions the optimal solution can be arrived at [18].

Green architecture and sustainable development is the inexorable trend for the future of architecture design, the ultimate goal of the beauty of architecture is "of the nation, of the world" and so ultimately, what energy saving and environment protection embodies is "of the nature, of the human race" [33].

\section{Sustainable Architecture and the Reasons of Crisis}

In many ways it offers a sustainable, climate outlook proposed. "Climate attitude" of man as a creature of earth, reduced need for comfort climate [20]. So, we find out that the principles of sustainable are on the same direction of that of the vernacular as; (the relation between the built environment and the surrounding nature). The change of ecology, mixing culture, technology and economic development has changed the vernacular architecture.

The effects are related to each other, the ecology is affected by the technology then the technology is affected by the condition of economic. Economic also brought effect to the culture and so on. The architectonic concepts have been pronouncedly affected by multifarious cultural influences brought along by several invaders, colonizers, missionaries, merchants and traders. Traditionally the most significant foreign architectural influences have affected the building 
styles and techniques [1].

The main solution of sustainable architecture is environmental look. This perspective leads to human declineinto a material subjectwhoseeks comfort, and ignores his essence. We have to consider our culture, identity and so on as well as the environment. Iran's architecture is full of treasures, made by our ancestors, and without these treasures a building is just steel,brick,cement and naturally nonsense [11].

In addition, the lack of any theocracyfor modern man imposes him to identity crisis, whichis born of western culture and relations [23].

Ahmadi thinks postmodernism is a conscious form of thatcrisis and the difference between modernism and postmodernism is in their definition of identity and change [4]. Identity crisis in architecture is because of form and content Incompatibility in a space without target and adequate identity basic pillars [23].

Titus Burckhardt [8] declares that there is crisis in both of The Christian and The Islamic art, he says "Christian art has been corrupted by the loss of its spiritual principles; Islamic art gradually disappears because of the destruction of the traditional crafts.".

Nasr [22] like most of modernity critics, thinks the mythic situation of primitive human was the best for him, In fact he destroyed Philosophy and civilizationas a result of rebellion against Godand brought himself into crisis and destruction. "To identify with a place primarily means to be open to its character or 'genius loci' and to have a place in common means to share the experiences of the local character, finally, means to adapt new buildings to his character" [24]. So in concept of sustainable architecture, every building with any ideas should adapt the genius loci of the place and avoid presenting itself as opposing element. finally it can be the sign of identity for the place.

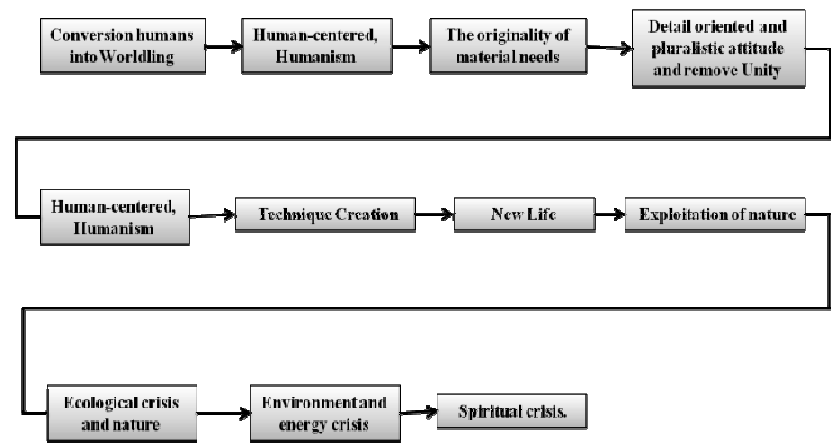

Figure 3. Crisis in the West of culture and civilization from viewpoint $d r$. Nasr, Noghrekar, 2008

\section{Crisis Making Factors in Environment Zone}

Holiness and holy spaces are the broadest and most generous holy space is environment which is made by a generous God. It's a place that the connection between our world with other world,sky with earth, and God's world with dead world become possible. [29]. According to Professor Nasr [21], crisis of the natural environment is the external manifestation of the crisis in psyche of men and women who have disregarded sky for the sake of earth, and now are on the threshold of destructing the atmosphere of the earth, too. This kind of crisis not only needs dialectical and formal solutions, but also needs death and renaissance of the modernist and his worldview, and the natural world should be changed to its firs form which ever have been; that is, in a sacred form reflexing creative divine forces. It is the common belief that to save the holiness of the life, the sacred entity of the nature should be noted that means re-scarifying the nature, but does not mean that we should bestow sacredness to the nature, because this work is out of human capability, but that we should take aside curtains of ignorance of pride which hide its holiness from humankind's vision. (see in Figure 3)

Destruction of the holy identity of the nature results in the cruelty of our relation with earth and place. The modern man has lost mythologic that have been very important for the primitive man, and also picture of the collective life and its values. Forces, limits and bottlenecks are much more difficult and bonds between form, culture and behavior have been weakened or only tracking and specifying of it has become difficult [28].

\section{Discussion and Conclusion}

It seems that constant development is the solution of society's condition, but provided that it be in accordance to dominant principles and thought of the society. The present paper has discussed the affective models on the constant development and the factors that bring about crisis, and tries with a comprehensive view tries to solve the present problems. Constant architecture was provided for developing countries with a modern idea, while this view is like the postmodern view, and the resultant model of the constant architecture is in accordance to treasures of the past generations with regard to todays technology. The issues in thepresent era direct the human being towards delusive and ephemeral ideals, and disappoints him in walking the endless way of the existence, the modern man is incapable of responding to his sentiments and mentalities resulting from mental excitements and disagreeables of this era, and heads towards technology in order to satisfy his needs under the aegis of technology. This positivist view regarding architecture results in receding of human being from himself and creates crisis. The mankind can only answer to the crisis of identity and personality which looks at the environment and his belongings as tradition, religion and history, and to follow a correct and suitable model in order to reach mental tranquility. However, this view somehow results in turning from mechanic thought and inductive reason towards mentality and instinct. Therefore, for a constant design, the architecture has duty to take a comprehensive look at the three dimensions of the environment, economy, society and culture. 


\section{References}

[1] Abdel Aziz. Indjy M.Shawket,(2011). New strategy of upgrading slum areas in developing countries using vernacular trends to achieve a sustainable housing development. Energy Procedia 6, 228-23.

[2] Abidin, N. Z., Pasquire, C.L.,(2007). Revolutionize value management: a mode towards sustain- ability. Int. J. Project Manage. 25, 275-282.

[3] Adhiutama, Akbar., Kiyoshi Dowaki.,(2013). Community empowerment through appropriate technology: sustaining the sustainable development. Procedia Environmental Sciences $17,1007-1016$.

[4] Ahmadi, B.(2012).Structure and interpretation of the text. Center Publication, Fourteenth Prt .

[5] Asayesh, M. ,(2010). In the world of architecture.Abadi journal, No.68, Twentieth year.

[6] Beiser, F., Boy, A., Zeel, D., Zhivane, Zh., Foster, M.(2006). Take the Enlightenment modernity and its discontent (Mentality, wisdom and beauty).translated by Zamiran,M., Tehran,Alam Publications, first edition.

[7] Boyko, C., Cooper, R., Davey, C.,Wootton, A., (2006). Addressing sustainability early in the urban design process. Manage. Environ. Qual. An Int. J. 17 (6).

[8] Burckhardt, T.(1970). Spirit of Islamic Art.translated by Nasr, H., Discussions of religious art journal, VOl.2, Tehran .

[9] Chen, J.J., Chambers, D.C., (1999). Sustainability and the impact of Chinese policy initiatives upon construction. Cons. Manage. Econ. 17.

[10] Fikret oglu Huseynov,emir.(2011). Planning of sustainable cities in view of green architecture. Procedia Engineering 21,534 - 542. 2011 International Conference on Green Buildings and Sustainable Cities

[11] Falamaki, M., M. ,(2006). Formation architecture - the experiences of Iran and the West.Faza publication, Second Edition, Tehran.

[12] Gloet, M., (2006). knowledge management and the links to HRM: developing leadership and management capabilities to support sustainability. Manag. Res.News29 (7).

[13] Gorji Mahlabani, Y., (2010). Architectural criticism in the field of environmental and sustainable. Community of Scientific Architecture and Urbanism of Iran,No.1.

[14] Handy, C. ,(1990). The Age of Unreason. Translated by Mokhbar,A. ,Harvard Business school Press.

[15] Haghighi Boroujeni,S., (2010). Imposition of Architecture to the route of Sustainable Development. Quarterly journal of Architecture and Urbanism,VOL.20 ,No.68.

[16] Hengrasmee, S., (2007).The study of Sustaiable architectural design in Thailand. Faculty of Architecture and Planning, Thammasat -University, Journal of Architectural/Planning Research and Studies Volume 5. Issue 1,

[17] Hojjat, I. ,(2005). Man 's identity, the identity of processor.Honar-Haye-Ziba Journal, No.23, Tehran.
[18] Krishan, Arvind., Pashim Tewari.(1998). Process of Design For Sustainable Architecture And Contemporary Solutions ,PERGAMON Renewable Energy I5,407-412. Process OF Design For Sustainable Architecture And Contemporary Solutions.

[19] Lombardi, P.L.,(2001). Responsibilities towards the coming generations: forming a new creed. Urban Design Stud. 7.

[20] Memariyan, G.,(2008). In the fullness of Theoretical Architecture.Sorosh Danesh Publication, Third Edition, Tehran.

[21] Nasr, H., (2007). Man and Nature.Translated by Rahmati, E. ,Ney publication, Tehran.

[22] Nasr, H., (2006). spirituality amorous. Translated by Dinparast, M., Kavir Publication, second Edition.

[23] Noghrekar,A. ,(2008). Introduction to Islamic identity in architecture and urbanism. Department of Housing and Urban Development publication, first Edition.

[24] Norberg-shulz, C., (2010).The concept of Dwelling on the Way to Figurative Architecture. Translated by AmirYarahmadi, M., Third Edition ,Agah publishing house,Tehran.

[25] Ofori, G., Briffett, C., Gang, G., Ranasinghe, M.,(2000). Impact of ISO 14000 on construction enterprises in Singapore. Cons. Manag. Econ. 18.

[26] Parkin, S.,(2000). Sustainable development: the concept and the practical challenge. In: Paper Presented at the Proceedings of the Institution of Civil Engineers, Civil Engineering.

[27] PourMokhtar,A.,(2012).Recognition of the concept of sustainability and sustainable development in the Iranian Architecture and Urbanism. Quarterly journal of Architecture and Urbanism,VOL.21,No.72\&73.

[28] Rapoport, A. (2009). Cultural Anthropology. Translated by Khosro Afzaliyan, Herfe Publication, first Edition.

[29] Rahnavard, z. ,Rahbarniya, Z., (2006). Sacred Art confronted with technology. Honar-Haye-Ziba Journal, No.26,pp.101-108.

[30] Roufechaei, Kamand M., Abu Hassan Abu Bakar, Amin Akhavan Tabassi, (2013). Energy-efficient design for sustainable housing development. Journal of Cleaner Production xxx,1-9. Journal of Cleaner Production xxx.

[31] Shariati, A.(2005). New Century Properties. Publication Chpbakhsh, seventeen Edition, Tehran.

[32] Vanags,jains., Ilona Butane.,(2013). Major Aspects of Development of Sustainable Investment Environment in Real Estate Industry. Procedia Engineering 57, 1223 - 1229. 11th International Conference on Modern Building Materials, Structures and Techniques, MBMST 2013.

[33] Wang zhe, Zhou li, Shi jing. (2011). On the beauty of green expo architecture and sustainable development-taking "China Pavilion" as an example. Procedia Engineering 21,163-167. 2011 International Conference on Green Buildings and Sustainable Cities.

[34] Weihong Li. (2011). Sustainable design for low carbon architecture .Elesvier Procedia Environmental Sciences $5,173-177.2010$ International workshop from the International Congress on Environmental Modeling and Software (iEMSs2010). 
[35] Zandiye, M., Parvardinezhad, S.,(2010). Sustainable development concepts in residential architecture in Iran, Housing and Rural Environment Journal.
[36] Zhou, L., Lowe, D. J., (2003). Economic challenges of sustainable construction. In: Paper Presented at the RICS Foundation Construction and Building Research Conference. University of Wolverhampton. 